\title{
Assessment of Mental Health in Children with Developmental Coordination Disorder in Indian Contexr - A Pilot Study
}

\author{
Ganapathy sankar $\mathbf{U}^{1}$ and Monisha $\mathbf{R}^{* 2}$ \\ ${ }^{1}$ Professor And Dean, Srm Institute of Science and Technology, India \\ ${ }^{2}$ Assistant Professor, Srm College of Physiotherapy, India
}

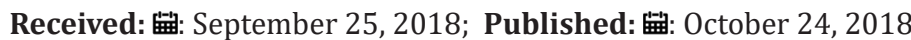

*Corresponding author: Monisha R, Assistant Professor, Srm College of Physiotherapy, India

\begin{abstract}
Background: Children with DCD were reported to be socially awkward and clumsy and they have poor social well-being. These children isolate themselves from their peer groups and even with in the family, they experience difficulty to communicate the needs.

Methodology: After getting informed consent signed from 10 parents of children aged 6 years with Developmental coordination Disorder, (DCDQ) Developmental coordination disorder questionnaire has been administered to all the selected samples mental health assessment of these children has performed with strength and difficulties questionnaire.

Discussion: Strength and difficulty questionnaire has been assigned to both teachers and parents to evaluate in detail regarding the emotional and behavioral problems faced by the children with Developmental coordination Disorder. When teachers and parents report has been compared by ICC, teachers reported that mental health of children were affected to a greater extent.
\end{abstract}

Conclusion: The present study demonstrated that various forms of mental health issues faced by children with DCD.

\section{Introduction}

Child diagnosed with Developmental coordination disorder possess motor coordination difficulties. This difficulty in motor coordination is expected to be less than the chronological age matched motor performance sequencing and organizing. These children were reported to be socially awkward and clumsy and they have poor social well-being. These children isolate themselves from their peer groups and even with in the family, they experience difficulty to communicate the needs. These children have innumerous difficulties faced with the normal activities of daily living. Even while walking these children experience fall and they have fear to walk and to get exposed to a new environment [1] (Figures $1 \&$ 2). Motor coordination persist in all the activity of daily living despite of having IQ of greater than $70 \%$ for all the children with DCD. They often experience difficulty in participating in simpler activities of daily living with peer groups, like riding a bicycle, jogging etc. because of the avoidance from their peer group members these children experience social isolation and they were physically inactive and tends to be sedentary in their activity of daily living [2].

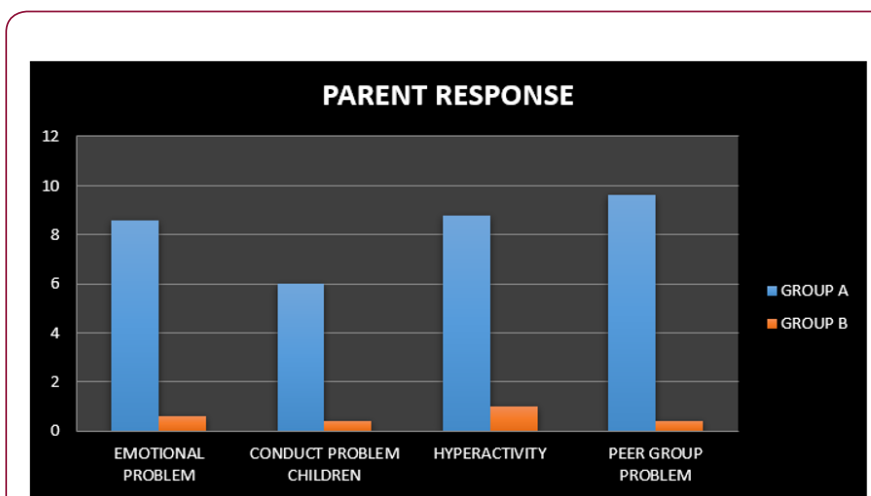

Figure 1: Parent Reported Measure for Children with Dcd And Non-Dcd Using Strength and Difficulty Questionnaire. 


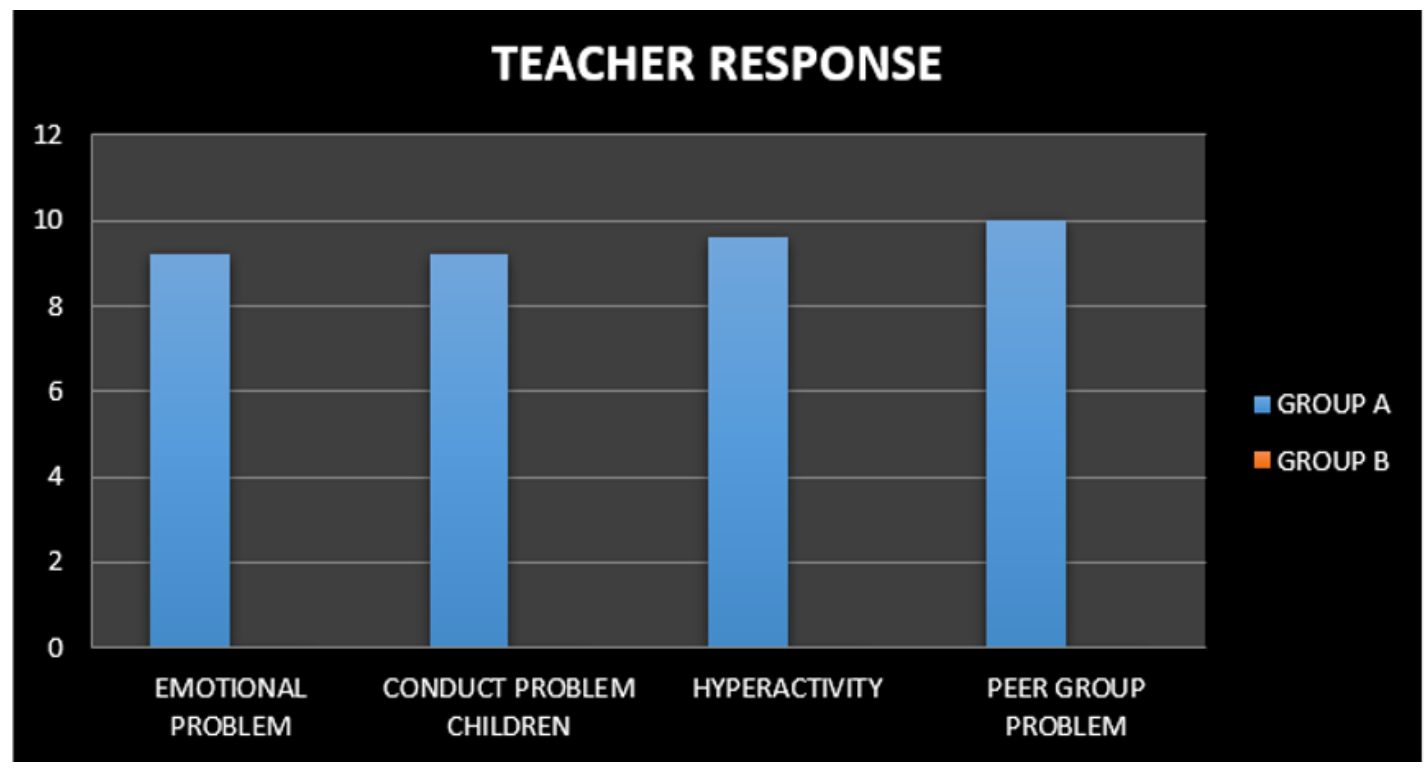

Figure 2: Teacher Reported Measure for Children with Dcd And Non-Dcd Using Strength and Difficulty Questionnaire.

None of the researchers has paid much attention to the mental health issues in children with DCD in addition to their motor coordination problem, these children experience psychological distress due to their difficulty in motor sequencing, timing and organization. They have anxiety and depressive symptoms as they experience poor academic outcome due to their poor handwriting skill and reading. These children much more difficulty with academic achievement. They also have cardio-vascular disease risk as the age advances, these children avoid play with their peer group and the physical activity is very poor because of the motor coordination difficulty [3] (Figure 3). Mental health is needed to be assessed in children with Developmental coordination disorder, as the symptoms of depression and anxiety needed to be ruled out and proper treatment intervention to be delivered to them at the earliest to avoid negative consequences of the disorder. Mental health problem is always considered to be hidden in all the children with developmental coordination disorder. There is a tremendous need to identify children's mental health feature to avoid social negativism and substance abuse [4]. Hence the current study has been done to evaluate the mental health in children with developmental coordination disorder (Figure 4).

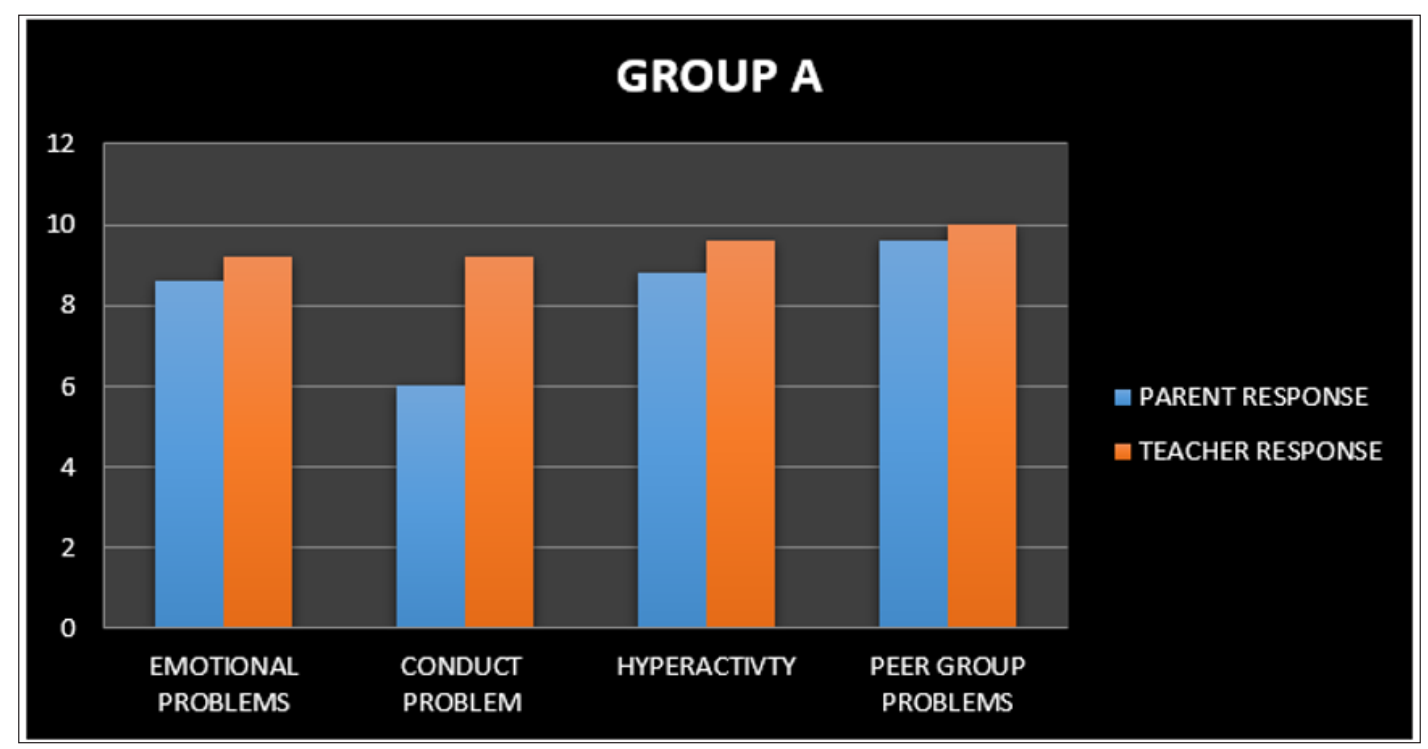

Figure 3: Teacher and Parent Reported Measure for Children With Dcd Using Strength And Difficulty Questionnaire. 


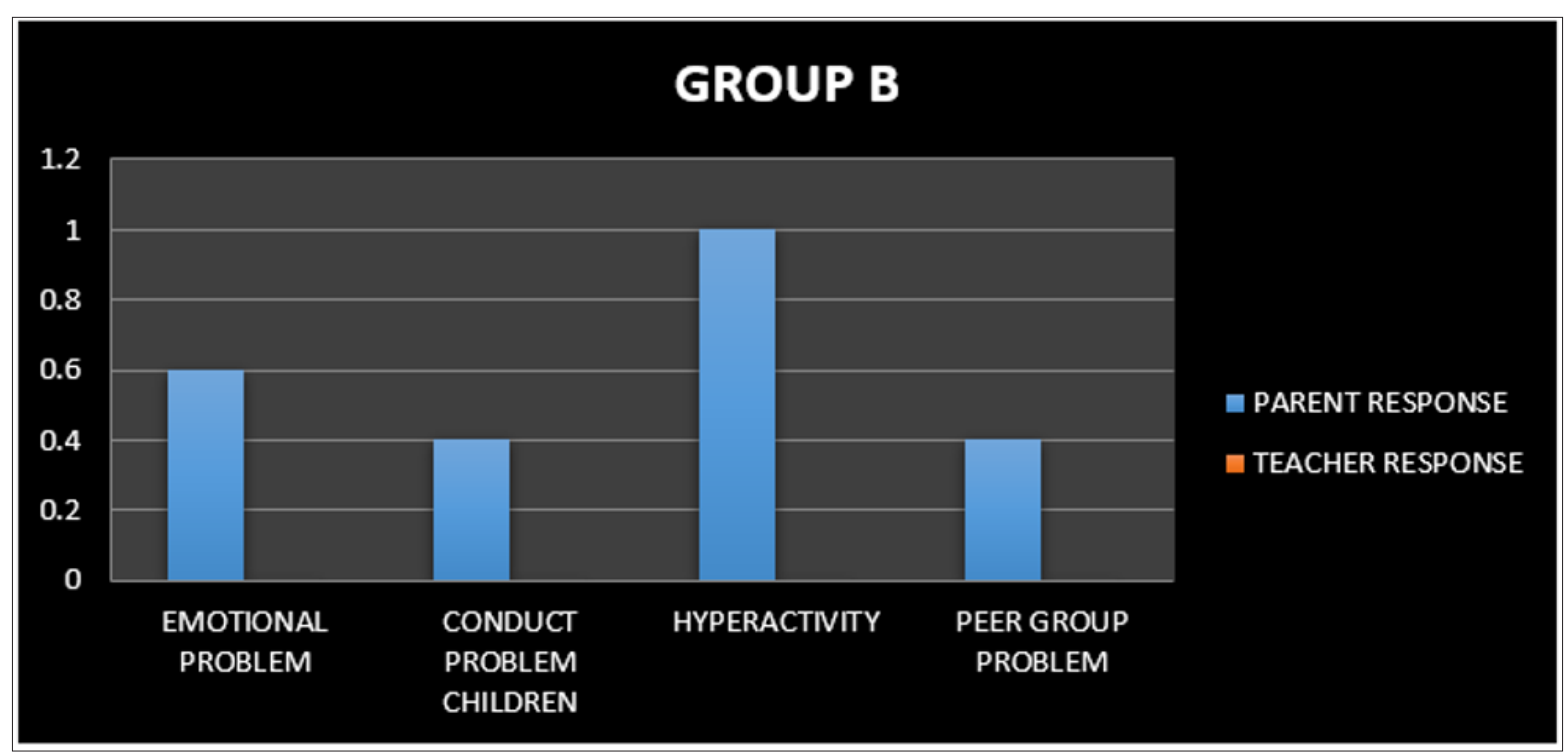

Figure 4: Teacher and Parent Reported Measure for Children with Non-Dcd Using Strength and Difficulty Questionnaire.

\section{Methodology}

After getting informed consent signed from 10 parents of children aged 6 years with Developmental coordination Disorder, (DCDQ) Developmental coordination disorder questionnaire has been administered to all the selected samples from primary schools in and around Chennai from 2018 January to 2018 July. After the baseline evaluation with DCDQ these children have been classified as DCD and NON-DCD population. 5 children were found to have DCD instead of having IQ of greater than $80 \%$ evaluated with Kaufman Brief Intelligence Test. They were included into GROUP $A$ and the remaining 5 children with normal intelligence scoring without DCD were included into GROUP B (Table 1).

Table 1: Parent and Teacher Reported Measure on Emotional Symptoms for Children with Dcd and Non-Dcd Using Strength and Difficulty Questionnaire.

\begin{tabular}{|c|c|c|c|c|}
\hline \multirow{2}{*}{ S. No } & \multicolumn{2}{|c|}{ SDQ-Parent } & \multicolumn{2}{c|}{ SDQ- Teacher } \\
\cline { 2 - 5 } & Group A & Group B & Group A & Group B \\
\hline 1. & 8 & 0 & 9 & 0 \\
\hline 2. & 7 & 1 & 9 & 0 \\
\hline 3. & 10 & 2 & 9 & 0 \\
\hline 4. & 10 & 0 & 9 & 0 \\
\hline 5. & 8 & 0 & 10 & 0 \\
\hline
\end{tabular}

Mental health assessment of these children has performed with strength and difficulties questionnaire [5]. SDQ is a reliable and valid assessment method used in children with DCD. It is a self-reported questionnaire used commonly in children and adolescents. Current study employed parent reported measures for children within the age group of 04-10 years component of SDQ. Totally 5 components have been assessed to analyze the mental health of children with developmental coordination disorder (Table 2). Teachers reported measures for children's -SDQ has been evaluated with teachers and has been submitted to the researcher. Parent and teachers scoring on SDQ can be used for final analysis of mental health in children with DCD [6].

Table 2: Parent and Teacher Reported Measure on Conduct Problem for Children with Dcd and Non-Dcd Using Strength and Difficulty Questionnaire.

\begin{tabular}{|c|c|c|c|c|}
\hline \multirow{2}{*}{ S. No } & \multicolumn{2}{|c|}{ SDQ-Parent } & \multicolumn{2}{c|}{ SDQ- Teacher } \\
\cline { 2 - 5 } & Group A & Group B & Group A & Group B \\
\hline 1. & 6 & 0 & 9 & 0 \\
\hline 2. & 5 & 1 & 8 & 0 \\
\hline 3. & 7 & 1 & 9 & 0 \\
\hline 4. & 6 & 0 & 10 & 0 \\
\hline 5. & 6 & 0 & 10 & 0 \\
\hline
\end{tabular}

\section{Discussion}

Strength and difficulty questionnaire have been assigned to both teachers and parents to evaluate in detail regarding the emotional and behavioral problems faced by the children with Developmental coordination Disorder [7] (Table 3). When teachers and parents report has been compared by statistical evaluation, teachers reported that mental health of children were affected to a greater extent. Parents too has reported that children with DCD has severe mental distress and were affected to a maximum extent in peer group problems. The results obtained in the current study is not in line with the study done by Laura et al, in 2017. She has done a research trial on emotional and behavioral problems in children with Developmental coordination disorder in UK [8] (Tables 4 \& 5). Analyses of the mental health of these children with DCD is the mandatory need for the parents and teachers, as these children isolate themselves from their peer group and experiences negative consequences on academics, physical and mental health. 
Table 3: Parent and Teacher Reported Measure on Hyperactivity for Children with Dcd And Non-Dcd Using Strength And Difficulty Questionnaire.

\begin{tabular}{|c|c|c|c|c|}
\hline \multirow{2}{*}{ S. No } & \multicolumn{2}{|c|}{ SDQ-Parent } & \multicolumn{2}{c|}{ SDQ- Teacher } \\
\cline { 2 - 5 } & Group A & Group B & Group A & Group B \\
\hline 1. & 10 & 0 & 9 & 0 \\
\hline 2. & 10 & 1 & 10 & 0 \\
\hline 3. & 8 & 1 & 9 & 0 \\
\hline 4. & 8 & 1 & 10 & 0 \\
\hline 5. & 8 & 2 & 10 & 0 \\
\hline
\end{tabular}

Table 4: Parent and Teacher Reported Measure on Peer Group Problem for Children With Dcd And Non-Dcd Using Strength And Difficulty Questionnaire.

\begin{tabular}{|c|c|c|c|c|}
\hline \multirow{2}{*}{ S. No } & \multicolumn{2}{|c|}{ SDQ-Parent } & \multicolumn{2}{c|}{ SDQ- Teacher } \\
\cline { 2 - 5 } & Group A & Group B & Group A & Group B \\
\hline 1. & 10 & 0 & 10 & 0 \\
\hline 2. & 10 & 0 & 10 & 0 \\
\hline 3. & 10 & 1 & 10 & 0 \\
\hline 4. & 10 & 1 & 10 & 0 \\
\hline 5. & 8 & 0 & 10 & 0 \\
\hline
\end{tabular}

Table 5: Paired Samples Test.

\begin{tabular}{|c|c|c|c|c|c|c|c|c|c|}
\hline & & \multicolumn{8}{|c|}{ Paired Differences } \\
\hline & & \multirow[b]{2}{*}{ Mean } & \multirow[b]{2}{*}{ Std. Deviation } & \multicolumn{2}{|c|}{$\begin{array}{l}\text { 95\% Confidence Interval } \\
\text { of the Difference }\end{array}$} & \multirow[b]{2}{*}{ Upper } & \multirow[b]{2}{*}{$\mathbf{t}$} & \multirow[b]{2}{*}{ df } & \multirow[b]{2}{*}{ Sig. (2-tailed) } \\
\hline & & & & Std. Error Mean & Lower & & & & \\
\hline Pair 1 & $\begin{array}{l}\text { EMO PAR GRP A - EMO } \\
\text { TEACH GRP A }\end{array}$ & -.600 & 1.517 & .678 & -2.483 & 1.283 & -.885 & 4 & .426 \\
\hline Pair 2 & $\begin{array}{l}\text { EMO PAR GRP B - EMO } \\
\text { TEACH GRP B }\end{array}$ & .600 & .894 & .400 & -.511 & 1.711 & 1.500 & 4 & 208 \\
\hline Pair 3 & $\begin{array}{l}\text { CPC PAR GRP A - CPC } \\
\text { TEACH GRP A }\end{array}$ & -3.200 & .837 & .374 & -4.239 & -2.161 & -8.552 & 4 & .001 \\
\hline Pair 4 & $\begin{array}{l}\text { CPC PAR GRP B - CPC } \\
\text { TEACH GRP B }\end{array}$ & .400 & .548 & .245 & -.280 & 1.080 & 1.633 & 4 & .178 \\
\hline Pair 5 & $\begin{array}{c}\text { HYPER PAR GRP A - HYPER } \\
\text { TEACH GRP A }\end{array}$ & -.800 & 1.304 & .583 & -2.419 & .819 & -1.372 & 4 & .242 \\
\hline Pair 6 & $\begin{array}{c}\text { HYPER PAR GRP B - HYPER } \\
\text { TEACH GRP B }\end{array}$ & 1.000 & .707 & .316 & .122 & 1.878 & 3.162 & 4 & .034 \\
\hline Pair 7 & $\begin{array}{c}\text { PEER PAR GRP A - PEER } \\
\text { TEACH GRP A }\end{array}$ & -.400 & .894 & .400 & -1.511 & .711 & -1.000 & 4 & .374 \\
\hline Pair 8 & $\begin{array}{c}\text { PEER PAR GRP B - PEER } \\
\text { TEACH GRP B }\end{array}$ & .400 & .548 & .245 & -.280 & 1.080 & 1.633 & 4 & .178 \\
\hline
\end{tabular}

When individual analyzes of all $(n=5)$ samples has done, these children reported to have behavioral problem. Further studies are needed to assess the individual domains behind the emotional and behavioral problems experienced by children with DCD. By general observation it has been known that instead of having IQ of greater than $80 \%$ these children face difficulty in schooling and they experience problem in completing the task related to home and in school. They have trouble with organizing, sequencing and completing the task which has been performed easily by their peer group and high rate of depression, anxiety and low self-esteem has been reported. Further studies are needed with larger sample size to formulate the psychometric domains in children with developmental coordination disorder in Indian context. Future follow up of all the ten samples involved in the study has been planned.

\section{Conclusion}

The present study demonstrated that various forms of mental health issues faced by children with DCD.

\section{References}

1. Ganapathy Sankar U, Saritha S (2011) A study of prevalence of Developmental Coordination Disorder (DCD) at Kattankulathur, Chennai, Indian Journal of Physiotherapy and occupational therapy $5(1)$.

2. Ganapathy Sankar U (2018) The Prevalence of Developmental Coordination Disorder at Kattupakkam, Tamilnadu. IOSR Journal of Pharmacy 8(2): 49-52.

3. Ganapathy Shankar U, Monisha R (2018) Challenges in the Assessment of Children with Developmental Coordination Disorder (Dcd). Biomed J Sci\&Tech Res 6(5).

4. Ganapathy Sankar U, Monisha R (2018) Assessment of bilateral coordination in children with developmental coordination disorder in indian context. International Journal of Advanced Research In Medical \& Pharmaceutical Sciences 3(7).

5. Ganapathy sankar U, Monisha R (2018) Assessment of In-Hand Manipulation in children with Developmental Coordination Disorders in Indian Context. International Journal of Advanced Research In Medical \& Pharmaceutical Sciences 3(7).

6. (2013) American Psychiatric Association, Diagnostic and statistical manual of mental disorders ( $5^{\text {th }}$ edn.). Washington DC, USA. 
7. Berninger VW, Nielsen KH, Abbott RD, Wijsman E, Raskind W (2008) Writing problems in developmental dyslexia: Under-recognized and under-treated. Journal of School Psychology 46(1): 1-21.

\section{ISSN: 2574-1241}

DOI: $10.26717 / B J S T R .2018 .10 .001931$

Monisha R. Biomed J Sci \& Tech Res

(C) (i) This work is licensed under Creative

Submission Link: https://biomedres.us/submit-manuscript.php
8. Coltheart M, Rastle K, Perry C, Langdon R, Ziegler JC (2001) DRC: A dual route cascaded model of visual word recognition and reading aloud. Psychological Review 108(1): 204-256. 